\title{
GESTÃO E REIFICAÇÃO DOS HOMENS
}

\section{DO MAR}

FRANCIS KANASHIRO MENEGHETTI

Doutor em Educação pelo Programa de Pós-Graduação em Educação da Universidade Federal do Paraná (UFPR).

Professor do Programa de Pós-Graduação em Tecnologia da

Universidade Tecnológica Federal do Paraná (UTFPR).

Avenida Sete de Setembro, 3.165, DAGEE, Rebouças, Curitiba - PR - Brasil - CEP 80230-901

E-mail: fkmeneghetti@gmail.com

\section{JOSÉ HENRIQUE DE FARIA}

Doutor em Administração pela Faculdade de Economia, Administração e

Contabilidade da Universidade de São Paulo (FEA-USP)

Professor do Programa de Mestrado em Organizações e Desenvolvimento do

Centro Universitário das Faculdades Associadas de Ensino (PMOD-Unifae)

Rua 24 de maio 135, Rebouças, Curitiba - PR - Brasil - CEP 80230-080

E-mail: jhfaria@gmail.com

Este artigo pode ser copiado, distribuído, exibido, transmitido ou adaptado desde que citados, de forma clara e explícita, o nome da revista, a edição, o ano e as páginas nas quais o artigo foi publicado originalmente, mas sem sugerir que a RAM endosse a reutilização do artigo. Esse termo de licenciamento deve ser explicitado para os casos de reutilização ou distribuição para terceiros. Não é permitido o uso para fins comerciais. 


\section{RESUMO}

O homem constitui-se como homem porque é capaz de produzir seus meios de sobrevivência, dentre os quais o trabalho tem lugar central na constituição da sociedade. É por meio dele que os homens "dominam" a natureza e colocam-se na posição de senhores diante dela. A pesca artesanal pode ser considerada uma atividade "secundária" nos interesses de acumulação do capital e é justamente por isso que o estudo da comunidade dos pescadores artesanais da cidade de Matinhos, estado do Paraná, configura-se um dos locais privilegiados para se verificar como o trabalho (englobando a divisão do trabalho, a tecnologia e a forma de gestão) e a mercadoria (englobando a propriedade privada e o fetiche da mercadoria) se constituem nas múltiplas determinações do real e estão relacionadas ao processo de reificação social. Assim, o objetivo deste trabalho é compreender como ocorre o processo de reificação dos pescadores artesanais, pela análise das categorias definidas como múltiplas determinações do real, tendo em vista sua inserção econômica e sua exclusão social no sistema de capital. A base teórica do trabalho é constituída de autores como Marx, Lukács, Adorno, Faria, Horkheimer e Meszáros, entre outros. Esta é uma pesquisa qualitativa em uma comunidade de pescadores artesanais. Foi possível verificar na pesquisa que a reificação, entre os pescadores mais jovens, dá-se pelo conjunto dos elementos (relacionados ao trabalho e à mercadoria) responsáveis pela transformação do sujeito em instrumento do capital. É a transformação da condição de produtor para a de mercadoria, com todas as suas propriedades. A reificação está relacionada, ainda, ao trabalho alienado e, apesar da tendência hegemônica do sistema capitalista de produção, é possível identificar resistências em relação a esse processo de reificação.

\section{PALAVRAS-CHAVE}

Gestão; Pesca artesanal; Reificação; Alienação; Trabalho. 


\section{INTRODUÇÃO}

Para Marx (1983b), o homem necessita produzir seus próprios meios de subsistência material, ou seja, constitui-se como homem porque é capaz de produzir as condições materiais de sua existência por meio do trabalho. Nesse sentido, a categoria trabalho, entendida em sua materialidade histórica e dialética, permite definir o homem (ser humano) em sua identidade geral como expressão de sua condição ontológica. Essa condição, segundo Lukács (I979), confere ao trabalho lugar central na constituição da sociedade. É por meio da produção das condições sociais de existência, ou seja, do trabalho, que os homens "dominam" a natureza. Assim, historicamente, em cada modo de produção, o trabalho se apresenta não como trabalho em si, não em sua condição ontológica, mas como um elemento que engloba as relações coletivas de ordem social. Dessa forma, sob o modo capitalista de produção, o trabalho é caracterizado pelo fato de ser submetido à lógica do sistema de capital. A estrutura econômica configurada por esse sistema mascara, de diversas formas, as relações de subsunção formal e real do trabalho ao capital.

Em alguns setores de atividade ou áreas da economia, o sistema de capital (MÉSZÁROS, 2002) não apenas abdica de promover o que se chama de "alto grau de desenvolvimento das forças produtivas" ao não investir nestas, especialmente em razão de suas baixas taxas de acumulação, como também imprime sua ideologia em práticas que aparentemente não se enquadram como organizações produtivas tipicamente capitalistas. Tais atividades, para garantir a tendência de controle hegemônico do capital, são mantidas de forma periférica ou subordinada. Esse é o caso da pesca artesanal, como atividade componente de uma forma social de produção. A manutenção da pesca artesanal não intervém negativamente no processo de acumulação do capital ao não concorrer com este, ao mesmo tempo que sua produção excedente de valor de uso e de troca de subsistência é destinada a empreendimentos capitalistas a baixo custo.

Pela sua especificidade, o objeto deste estudo são os pescadores artesanais da cidade de Matinhos, estado do Paraná, pois estes não estão imunes às influências das transformações resultantes dos investimentos do sistema de capital em todas as áreas (economia, política, cultura e demais setores da vida social). A pesca artesanal, pensada ontologicamente, pode ser considerada atividade "secundária" nos interesses de acumulação do capital. Contudo, considerada sua atividade prática, ela compõe um sistema que se integra ao capitalismo. Justamente por isso, essa comunidade de pescadores representa um local privilegiado para se verificar como o trabalho (desde sua divisão, suas tecnologias, sua forma de gestão e seu produto), englobando a propriedade privada e o fetiche da mercadoria, constitui-se nas múltiplas determinações do real relacionadas ao processo de reificação social. 
Dessa forma, o objetivo central deste estudo é compreender como ocorre o processo de reificação dos pescadores artesanais da cidade de Matinhos, estado do Paraná, pela análise das categorias definidas como múltiplas determinações do real, tendo em vista sua inserção econômica e sua exclusão social do sistema de capital.

A pesca artesanal é definida, nesta pesquisa, como a atividade de captura e desembarque de todas as espécies aquáticas para comercialização. São utilizadas para tal fim embarcações e aparelhagens rudimentares ou simples, se comparadas com as tecnologias disponíveis nos grandes empreendimentos pesqueiros, seja no que se refere aos navios, como aos próprios processos de pesca (radares de identificação de cardumes, utilização de robôs etc.), de limpeza, embalagem e armazenamento. A forma de trabalho que prevalece na pesca artesanal pode ser considerada pré-capitalista pelo seu caráter de não assalariamento e pelo fato de alguns tripulantes terem remuneração por empreitada (diárias ou por produtividade) nos casos em que não se utiliza mão de obra familiar. As pescas são realizadas próximo à costa e sua duração média não ultrapassa seis horas diárias, devido à pequena autonomia das embarcações.

Para a realização deste estudo de caso, conforme explicitado adiante, a abordagem qualitativa foi a escolhida, apoiada em técnicas de entrevista e análise de conteúdo. Indicações quantitativas utilizadas não se referem à aplicação de métodos estatísticos, mas a formas de sistematização das informações.

A abordagem teórica que sustenta este estudo tem origem na Teoria Crítica da primeira geração da chamada Escola de Frankfurt e segue no âmbito do marxismo ocidental. Em outras palavras, os conceitos de reificação, alienação e trabalho aqui empregados procedem de uma linha de análise conhecida como marxismo ocidental. A escolha dessa concepção teórica deve-se à sua condição de abordagem crítica de uma realidade que se enquadra sob o comando do sistema de capital, ainda que a forma de produção estudada seja pré-capitalista (artesanal). É com os teóricos da Escola de Frankfurt que as análises de atividades não tipicamente capitalistas são estudadas pela primeira vez no âmbito do marxismo como inseridas no sistema de capital, sendo a mais conhecida delas a indústria cultural.

O método de investigação, no presente caso, decorre de uma epistemologia que se apoia na primazia do real. Para este estudo em particular, nessa linha de abordagem teórica, entende-se que as técnicas que melhor propiciam a identificação da realidade são de natureza qualitativa, ainda que a Teoria Crítica trabalhe com métodos quantitativos, como na clássica pesquisa sobre a personalidade autoritária conduzida por Adorno e seus colaboradores em I950 nos Estados Unidos. 


\section{A COMUNIDAdE DE PESCADORES}

A comunidade de pescadores pesquisada localiza-se na cidade de Matinhos, litoral paranaense. Trata-se de um balneário, sem atividades produtivas relevantes, conforme pode ser deduzido dos dados do censo do IBGE. A atividade econômica principal é o turismo, com ênfase nas temporadas de verão. Matinhos possui um campus da Universidade Federal do Paraná, chamado campus Litoral, inaugurado em 2007 , o que ainda não permite avaliar seu impacto na vida econômica e social do município, embora se reconheça sua importância.

A população estimada é de 32 mil habitantes fora da temporada de verão, quando a população pode chegar a I20 mil pessoas. A pesca representa, fora de temporada, uma atividade econômica importante para a sobrevivência de parte da população permanente da cidade. Todavia, o caráter artesanal e a concorrência com os grandes barcos pesqueiros vindos do Rio Grande do Sul e de Santa Catarina dificultam o trabalho dos pescadores.

A população total de pescadores da comunidade é de 210. Para a pesquisa, os pescadores foram classificados em três grupos (faixa de tempo de experiência, em anos) em relação à atividade da pesca artesanal. Primeiro, os pescadores mais jovens têm menos de io anos de experiência e totalizam i7o pescadores na comunidade. Segundo, os pescadores intermediários têm entre II e 39 anos de experiência e são 34 pescadores. Os mais experientes têm mais de 40 anos de atividade e são 6 pescadores no total. O Quadro I resume esse perfil dos pescadores.

\section{QUADRO I}

PERFIL DA COMUNIDADE DOS PESCADORES DE MATINHOS POR TEMPO DE EXPERIÊNCIA (2009)

\begin{tabular}{cc}
\hline FAIXA DE TEMPO DE EXPERIÊNCIA, EM ANOS & $\begin{array}{c}\text { TEMPO MÉDIO DE EXPERIÊNCIA, } \\
\text { EM ANOS, DOS ENTREVISTADOS }\end{array}$ \\
\hline Entre 0 e 10 anos & 8,00 \\
\hline Entre 11 e 39 anos & 18,60 \\
\hline Mais de 40 anos & 44,67 \\
\hline Teste F & 1692,561 \\
Significância & $p<0,001$ \\
Eta & $99,2 \%$ \\
\hline
\end{tabular}

Eta$^{2}$ : Percentual de explicação das categorias em relação a variável quantitativa. O alto valor do Eta ${ }^{2}$ está associado à grande homogeneidade das faixas.

Fonte: Elaborado pelos autores. 
Como se pode observar, o sentido atribuído ao trabalho está relacionado com o tempo de experiência dos pescadores quando se compara a média de experiência deles. Esse cuidado foi importante para a seleção dos entrevistados. Nesse sentido, as entrevistas com 29 pescadores obedeceram à classificação por faixa de tempo de experiência, em anos. Tal classificação, quando exposta à variância explicada pelo $\mathrm{Eta}^{2}$, condiciona o valor médio, ou seja, o alto valor do ta $^{2}$ está associado a grande homogeneidade das faixas.

A comunidade de pescadores do município de Matinhos é formada, essencialmente, por nativos da região litorânea do Paraná e de suas fronteiras próximas (nordeste de Santa Catarina e sudeste de São Paulo). A pesca é uma atividade tradicional dos caiçaras, grupo indígena que habitava a região e que, embora extinto como grupo, possui descendentes que mantêm a atividade pesqueira. As faixas de tempo de experiência na atividade da pesca artesanal indicam que, não obstante a transformação dessa atividade em empreendimento capitalista de alto composto tecnológico, essa forma de produção das condições materiais de existência ainda continua sendo a principal dessas famílias de pescadores.

\section{B MÉTODO DE PESQUISA}

A escolha dos pescadores para a realização das entrevistas foi definida por adesão voluntária deles, observando o critério da participação das faixas de tempo na definição dos entrevistados. Contudo, foi necessário optar por enfatizar os resultados das entrevistas dos pescadores mais jovens e dos mais experientes, já que as respostas dos pescadores com experiência intermediária foram pouco relevantes em relação aos objetivos da pesquisa. Isso se deu porque os pescadores dessa faixa, embora entrevistados, não apresentaram nenhuma questão que não tivesse mais bem esclarecida ou com os mais jovens ou com os mais experientes. Dessa forma, essas entrevistas foram descartadas do conjunto, restando apenas as 29 mencionadas. No texto, os pescadores mais experientes serão indicados pela sigla PE e os pescadores mais jovens pela sigla GPJ.

Esta é uma pesquisa que se enquadra em um estudo de caso, sendo a técnica de coleta e análise das informações de natureza qualitativa, a partir da análise dos depoimentos, segundo procedimentos recomendados por Bardin (I979). Nas entrevistas realizadas com pescadores com menor tempo de experiência foi necessária, inicialmente, uma conversa informal. Após realizar algumas entrevistas individuais, percebeu-se que os pescadores, tanto os mais novos como os mais experientes, ficariam mais à vontade e predispostos a responder com mais efetividade às perguntas caso estivessem em grupo.

Foram realizadas seis entrevistas individuais e três procedimentos de entrevistas coletivas. Nos três procedimentos em instância coletiva, as questões for- 
muladas foram respondidas e debatidas entre os participantes com intervenção apenas orientadora do tema central pelos pesquisadores. O primeiro procedimento coletivo foi realizado com cinco pescadores; o segundo, com sete; e o terceiro, com II pescadores. No primeiro procedimento de entrevista coletiva não foram utilizadas questões estruturadas, pois o que se pretendia era uma "aproximação precária com o objeto" (FARIA, 20II, p. 25). Nos outros dois procedimentos foram apresentadas questões semiestruturadas.Verificou-se que a condição de entrevista coletiva, na qual os pescadores puderam trocar ideias e discutir suas percepções, viabilizou o direcionamento das respostas para as categorias centrais do trabalho.

No caso das entrevistas individuais com os seis pescadores, foram propostas questões não estruturadas e semiestruturadas, porque havia o interesse dos pesquisadores na perspectiva da história vivida como elemento fundamental para a compreensão da realidade estudada. Embora nessas entrevistas tenham se destacado as histórias individuais, a pesquisa procurou valorizar os aspectos das entrevistas que tinham conexão com a definição temática.

É importante destacar que os pescadores, de imediato, foram receptivos e colaboraram com as entrevistas, ainda que, em princípio, tenham se mostrado um pouco receosos. Contudo, a vontade de contar suas "histórias de pescadores", de mostrar seu trabalho, de se sentirem valorizados pelo interesse de alguém pelo seu mundo possibilitou aproximação rápida e extrema colaboração, sem nenhuma forma de resistência.

As entrevistas não estruturadas (denominadas aqui entrevistas de aproximação) com seis pescadores visavam, como já referido, uma "aproximação precária com a realidade" pesquisada (FARIA, 20II, p. 26). Nesse momento, não foram enfatizadas as faixas consideradas centrais na pesquisa, pois a finalidade dessas primeiras entrevistas foi possibilitar a aproximação e despertar confiança mútua entre os pesquisadores e os entrevistados. Já nas demais entrevistas individuais posteriores foram propostas questões semiestruturadas com cada pescador, em momentos diferentes (entrevista de retorno para maiores esclarecimentos), abordando as questões centrais da pesquisa.

Este é um estudo de caso particular, sendo o nível de análise a categoria social de pescadores que realizam uma atividade artesanal e a unidade de análise aquela constituída pelo grupo de pescadores artesanais da cidade de Matinhos, estado do Paraná. Adotou-se o procedimento de pesquisa de natureza qualitativa, tendo em vista que ele valoriza o ambiente natural como fonte direta dos dados e busca compreender essencialmente o significado dos depoimentos dos pescadores estudados no contexto das atividades.

Para a análise das informações obtidas, procurou-se descrever a complexidade do problema, analisar a interação dos elementos constitutivos das categorias, 
compreender os processos de trabalho e as condições de existência do grupo social estudado e conhecer, em maior profundidade, as particularidades do comportamento dos pescadores e suas vivências. A adoção desses procedimentos se justifica porquanto a análise dos dados se torna mais coerente, pois neste estudo a necessidade de se compreender o conteúdo vivido dos depoimentos e a dinâmica dos grupos focais foi fundamental. Foram realizadas confrontações que permitissem o tensionamento entre os conteúdos das entrevistas, nas quais se procurou encontrar coerências e inconsistências, de forma que na análise dos dados fosse possível obter maior abrangência na descrição, explicação e compreensão do objeto de estudo.

As entrevistas foram, na maioria das vezes, gravadas e, quando não, foram realizados registros escritos dos depoimentos com a posterior conferência para verificar se as anotações correspondiam ao conteúdo desses depoimentos. As análises seguiram as técnicas descritas por Bardin (I979) quanto à abordagem não quantitativa. A análise de conteúdo é

[...] um conjunto de técnicas de análise das comunicações, visando obter, por procedimentos sistemáticos e objetivos de descrição do conteúdo das mensagens, indicadores, quantitativos ou não, que permitam a inferência de conhecimentos relativos às condições de produção/recepção (variáveis inferidas) destas mensagens (BARDIN, I979, p. 27).

No caso desta pesquisa, optou-se por "indicadores" não quantitativos. Bardin (I979) sugere a técnica da análise do discurso pertencente ao campo da análise de conteúdo. A autora argumenta que um discurso (ou conjunto de discursos) é determinado por condições de produção e por um sistema linguístico. Dessa forma, o discurso é determinado não só pelo referente, mas também pela posição do emissor da mensagem. As posições e lugares em que se encontram tanto o emissor quanto o receptor determinam a estrutura e a formação social que se relacionam na prática discursiva. Bardin (I979, p. 215), portanto, indica que se devem descobrir "as conexões que possam existir entre o exterior e o discurso, entre as relações de força e as relações de sentido, entre condições de produção e processos de produção".

A partir dos depoimentos foi possível compreender a totalidade do caso estudado nos limites do tema definido. Nesse sentido, a transcrição de alguns depoimentos não indica que eles constituem a prova definitiva da situação. A escolha dos depoimentos foi realizada quando eles continham a representação dos demais depoimentos, ou seja, quando refletiam o conjunto das opiniões e as sintetizavam de forma particular. 


\section{DESCRIÇÃO DOS MEIOS E DA ORGANIZAÇÃO DO TRABALHO: AS EMBARÇAÇOES E EQUIPAMENTOS E OS TIPOS DE PESCA}

\subsection{MEIOS DE TRABALHO: EMBARCAÇÕES E EQUIPAMENTOS}

A partir das entrevistas, os pescadores informaram as características técnicas e operacionais dos meios de trabalho de que dispõem, as quais são descritas a seguir:

\subsubsection{Embarcações e equipamentos}

- Canoas de madeira com comprimento entre 6 e io metros; motor de centro com potência entre II e $24 \mathrm{HP}$; tora única escavada; fundo quilhado e em forma de V.

- Botes entre 7 e io metros; motor de centro com potência entre 9 e 36 HP; de tábuas encaixadas de forma lisa; fundo quilhado ou chato; com guincho e tangones, dois por barco, utilizados para tração das redes de arrasto.

- Canoas de fibra de vidro, embora pouco utilizadas; têm entre 8 e 9 metros; motor de centro com potência entre II e $24 \mathrm{HP}$, fundo quilhado e em forma de V; fabricadas de resina sintética e fibra de vidro.

\subsubsection{Tipos de pesca}

Também a partir das entrevistas com os pescadores foi possível registrar basicamente três tipos de pesca, consideradas artesanais, na região. O processo de trabalho (tipo de pesca) descrito pelos pescadores é resumido a seguir:

- Pesca com utilização de redes de arrasto, utilizando-se pranchas (ou portas de madeira, quando de maior tamanho e constituídas por tábuas vazadas). Caracteriza-se pela utilização de malhas no ensacador, que varia de i a 6 centímetros entre nós opostos. São puxadas pela popa ou pelo costado, sempre no fundo do mar.

- Pesca com redes de emalhe, utilizando-se malhas que variam de 5 a 40 centímetros entre nós opostos, operando com algumas formas particulares: "caceio" (de superfície ou de fundo), que fica à deriva. Uma variação de caceio de fundo utilizado é o caracol, em que a rede é forçada em semicircunferência por uma de suas extremidades presa à embarcação. Outra forma 
é a de "fundeio", rede presa ao fundo por poitas de ferro. Nesse tipo, os panos interligados podem ultrapassar 3.500 metros de comprimento. Outra variação relatada de "caceio" para os estuários foi o "lance batido", com a disposição da rede em semicircunferência e com produção de estímulos sonoros (remo, motor) para a movimentação dos peixes de encontro à rede.

- Pesca com tarrafas, utilizando-se oito diferentes tamanhos de malha, que variam entre 2 e I 8 centímetros entre nós opostos. É utilizada nos estuários e na boca das baías, quando da entrada de tainhas (principalmente no inverno).

\section{REIFICAÇÃO E ALIENAÇÃO NO TRABALHO}

O trabalho, que inicialmente deveria apresentar-se como forma primeira do processo de esclarecimento e de emancipação social, é, na atual estrutura econômica, um mecanismo de alienação e de controle social. A reificação do indivíduo tem sua origem na dimensão social, mas é também nessa mesma sociedade que se pode encontrar as contradições e negações de suas características. Não há reificação sem a presença do outro, pois são os outros, no emaranhado das relações sociais, que estabelecem e que fornecem as múltiplas determinações do real, "condicionantes" que limitam as ações humanas.

A compreensão da reificação só é possível por meio de análise de âmbito social. Na perspectiva sugerida por Mészáros (2002), a instrumentalização dos sujeitos só se concretiza na medida em que alguns são destituídos da sua condição de sujeitos autônomos para ser subjugados pela dominação do outro, quase sempre configurada por objetos dos interesses do capital. Impiedosamente, o sistema capitalista, por meio da instrumentalização dos indivíduos, formaliza o processo de reificação escondendo os responsáveis por ele. O anonimato da violenta instrumentalização é a absolvição de um culpado sem identidade, pois, tal como a mercadoria, os agentes de sua constituição perdem-se no imediato percebido pelos indivíduos. Dialeticamente, ao mesmo tempo que a reificação se afirma como realidade objetiva da vida social, uma subjetividade responsável pela reprodução da aceitação desse processo precisa ser formada. Assim, a reificação constitui um processo objetivo, mas que precisa sedimentar-se no plano da subjetividade dos indivíduos. Vale ressaltar, contudo, que essa subjetividade nada tem de libertária, porque é ela que orienta, de forma pacificadora e sutil, a definição das falsas necessidades a ser supridas para manter a reprodução do sistema.

Dessa forma, é possível falar em uma subjetividade orientada para integrar o processo de reprodução sociometabólica do capital (MÉSZÁROS, 2002). Apesar 
de a subjetividade ter um apelo de ordem individual, o sistema de produção e consumo no capitalismo fomenta um conjunto de elementos específicos que integram as subjetividades dos indivíduos de forma a "orientar" e "manipular" processos inconscientes para concretização dos interesses objetivos do capital.

Assim, só a história, como fundamento principal do movimento de libertação, não é suficiente para libertar os homens dessa tendência totalizadora. O passado e o presente são responsáveis por narrar a história de um processo que tem origem, essencialmente, na relação de exploração do capital sobre o trabalho. Assim, a reificação é um processo cuja origem deve ser buscada nos primórdios da sociedade organizada e do uso de instrumentos. Contudo, a transformação de todos os produtos da atividade humana em mercadorias só se concretizou com a emergência da sociedade industrial. As funções outrora preenchidas pela razão objetiva, pela religião autoritária, ou pela metafísica, têm sido ocupadas pelos mecanismos reificantes do anônimo sistema econômico (HORKHEIMER, 2000, p. 48).

A reificação, portanto, prescinde de elementos substanciais oriundos da própria organização das relações de produção, sem, contudo, negligenciar a forma como esta orienta a subjetividade dos sujeitos sociais. Questões objetivas põem-se, destarte, como manifestação da forma como as condições de produção da existência humana se apresentam. Nesse contexto, o trabalho nos moldes do capitalismo é a centralidade que forma a ontologia do ser social. Os sujeitos dessa formação ontológica, segundo Lukács (I979), são seres sociais, que não se constituem como sujeitos porque se encontram dissociados das relações sociais que se consolidam e solidificam nas atividades de produção da existência.

Outro aspecto relevante para se levar em consideração é a forma como o capitalismo transforma e cria novas necessidades e como o trabalho é capaz de dinamizar os aspectos das subjetividades dos sujeitos. Ambos os aspectos estão no bojo da formação ontológica do ser social (LUKÁCS, I979). Em outras palavras, relacionada às novas necessidades e ao processo de reificação social, a "condição necessária do processo de coisificação é que toda a satisfação das necessidades se realize na sociedade na forma de tráfico de mercadorias" (LUKÁCS, i969, p. 98). O "mercado de trocas" dimensiona como as relações devem se estabelecer. O indivíduo cede espaço para os objetos produzidos em um sistema impessoal e instrumentalizador, que tem como característica central condicionar as relações sociais com base em uma organização objetiva externa aos indivíduos e sob o domínio de poucos.

As novas necessidades são internalizadas pela produção e pelo consumo acelerado de novas mercadorias. A realidade vivida pelos indivíduos é incorporada pelas modificações estéticas da mercadoria produzida no sistema capitalista de produção, ou seja, o produtor confunde-se com a mercadoria, pois ambos 
adquirem a mesma propriedade - o caráter de coisa, mesmo que o primeiro não tenha a propriedade do segundo (MÉSZÁROS, 2006).

De acordo com Mészáros (2006), o ser social é transformado em ser produtivo, mas voltado para atender a necessidades individuais, em que a mercadoria passa a ser mais importante que as relações sociais necessárias para produzi-la. A mercadoria como fim em si mesmo, para a satisfação das necessidades individuais, justifica o meio pelo qual é produzida. A mercadoria, sob o capital, torna-se mediadora das relações sociais. Assim, a consciência é transformada em produto do pensamento instrumentalizado pelas relações de troca em todos os níveis da vida em sociedade. Desde as relações afetivas primárias que se desenvolvem no âmbito da família até o plano das relações sociais, a gramática é ditada pela produção e consumo das mercadorias, as quais são transformadas em entes com propriedades e significados próprios e que independem da condição humana.

As trocas são corroboradas pela consciência com base no cálculo das utilidades e das consequências. A regra é a mesma definida pela ditadura do capital e seu código autoritário (FARIA, 2004). A mercadoria, portanto, é a própria condição final da existência humana no sistema capitalista de produção. Seu caráter fetichista se transfere para as relações que se estabelecem socialmente e no mundo do trabalho sob o sistema capitalista de produção (MARX, I983b). A forma como a produção de mercadorias se constitui é o elemento central na formação das múltiplas determinações do real.

Outro fator relacionado à reificação é a alienação do trabalhador. Marx (ig67) caracteriza o trabalho alienado de quatro formas: I. a relação do trabalhador com o produto do seu trabalho; 2. a expressão da relação do trabalho com o ato em si da produção no interior do processo de trabalho; 3. o objeto do trabalho, enquanto "objetivação da vida da espécie humana" (MÉSZÁROS, 2006, p. 20); 4. o estranhamento do homem em relação à natureza e a si mesmo.

Explicando de maneira simples, na primeira forma o produto do seu trabalho não lhe pertence. $O$ trabalhador vende sua força de trabalho por um salário e o produto do seu trabalho passa a pertencer ao capital. Nesse caso, a alienação do trabalhador em seu produto não significa apenas que o trabalho dele se converte em objeto, assumindo uma existência externa, mas, ainda, que existe independentemente, fora dele mesmo, e a ele estranho, e que se lhe opõe como uma força autônoma (MARX, I967, p. 9I).

Na segunda forma, o trabalho é externo ao trabalhador, não fazendo parte da sua natureza. O trabalhador não se realiza no trabalho, no processo de produção. O trabalhador nega-se a si mesmo, sofre em vez de ter a sensação de bem-estar no processo de trabalho. Na terceira forma, o trabalhador é objetivado para a vida pela ação transformadora do ato de produção. Sua humanidade se realiza porque é 
capaz de produzir suas condições materiais de sobrevivência, ao mesmo tempo que se desumaniza porque o trabalho objetivado não é definido por ele, ou seja, a forma e o meio de objetivação são dados pelo capital. Na quarta forma, o homem torna-se estranho à natureza, porque passa a modificá-la. Apresenta-se como "senhor" dela e exerce sua capacidade de impor sua vontade sobre os destinos da natureza. Todavia, o homem é parte da natureza e, ao impor sua vontade, cria uma relação estranha aos outros homens sem o mesmo poder de imposição de suas vontades. O trabalho alienado cria a subordinação dos homens sobre os homens, condicionada pelas diretrizes do capital.

Resumidamente, a reificação é a transformação dos indivíduos em coisas ou instrumentos. O indivíduo reificado é aquele em que seu Ser é dominado pelo processo de produção, conduzido pela relação capitalista de trabalho. A alienação expressa a forma pela qual o sujeito é reificado no trabalho. Considerando, portanto, a não posse do objeto que produz, a constituição do processo de produção como fonte de sofrimento ao invés de fonte de satisfação de necessidades materiais e psicológicas e a contradição do trabalho humano que, ao mesmo tempo desumaniza, tem-se o quadro da reificação. A esse se interliga também a constituição de uma superestrutura, cujo controle encontra-se fora do alcance do poder político do trabalhador coletivo em detrimento do domínio estabelecido nas condições do sistema de capital.

\section{GENEALOGIA DAS MÚLTIPLAS DETERMINAÇÕES DO REAL DOS HOMENS DO MAR}

A apropriação do real concreto pelo real pensado se faz com a mediação do pensamento (MARX, I983a). Para além da materialidade do real, a existência do imaginário e do imaterial também constituem as condições da percepção do sujeito sobre o concreto. Oriundo das relações de produção e das relações sociais definidas por aquela, o real se apresenta ao sujeito como uma multiplicidade, uma variedade e uma complexidade de fenômenos contraditórios em movimento. Na medida em que o modo de produção capitalista avança e se torna cada vez mais complexo, as instâncias superestruturais por ele construídas ganham novos contornos e nova dinâmica. Assim, as ideologias e as concepções políticas multiplicam-se e ganham conotações afirmativas na defesa do multiculturalismo, da diversidade, da efemeridade e de todas as características que apontem para a multiplicidade dos fenômenos concretos.

Nancy Fraser (2008) chama a atenção para o deslocamento das lutas sociais contemporâneas dos conflitos fundamentais para as lutas de gênero, identidade, 
multiculturalismo, entre outras, como se estas não estivessem abarcadas pelas lutas de classes sociais. É importante observar, nessa direção apontada por Fraser, que a tendência totalizadora do capitalismo diversifica e promove a multiplicidade no plano da aparência, pois ela é capaz de justificar a continuidade de um sistema que tem no centro da sua reprodução social a polarização entre capital e trabalho. Dito de outra maneira, o deslocamento da atenção, incluindo a analítica, da luta fundamental para conflitos específicos favorece a ideologia subjacente ao sistema de capital.

Outra discussão relevante refere-se ao entendimento de determinação. A tradução do termo em O capital de Marx (I99I) dá a ideia de um não voluntarismo, que destitui dos sujeitos a possibilidade de mudanças sociais por meio de organizações coletivas. Entretanto, determinação não é um termo que deve ser compreendido por um entendimento mecanicista, fatalista ou definitivo. As determinações são os elementos que exercem significativas influências sobre a definição de algo. As determinações não extinguem possibilidades, mas orientam efetivações que, em outras condições objetivas e subjetivas, dificilmente se realizariam.

Desse modo, falar em "Genealogia das múltiplas determinações do real" é compreender a origem e o movimento da práxis dos elementos significativos para a definição das múltiplas determinações apresentadas como reais para os sujeitos. Dito de outra forma, é entender o movimento contraditório das questões objetivas e subjetivas e como elas exercem significativa influência na formação dos sujeitos e na constituição da realidade.

Foi, portanto, com essa elaboração teórica e histórica que se tornou possível olhar para a realidade empírica do objeto proposto para o estudo e relacioná-la ao próprio movimento da história dos pescadores para definir as categorias das múltiplas determinações do real. Entre as categorias, destacam-se: I. o trabalho englobando a divisão do trabalho, a tecnologia, a forma de gestão, a hierarquia; 2. a mercadoria - englobando a propriedade privada, o fetiche da mercadoria, as relações de troca, o consumo, a estética da mercadoria; 3. o social-histórico englobando o imaginário social (espaço, tempo, vínculos sociais), a ideologia e a política.

\section{TRABALHO}

O processo de trabalho, de início, deve ser considerado independentemente de qualquer forma social determinada, pois se trata de um processo que ocorre entre o homem e a natureza, no qual ele regula e controla seu metabolismo (MARX, I983a). Quando o trabalhador emprega sua força de trabalho, ele o faz para produzir valor de uso. "A utilização da força de trabalho é o próprio trabalho" (MARX, I983b, p. I49). A divisão do trabalho somente se efetiva, de acordo com a 
concepção de Marx, com base na divisão clássica entre trabalho manual e intelectual. Uma das condições do processo de reificação é a confirmação e sedimentação dessa divisão. De fato, é possível perceber que na atividade dos pescadores ocorre "certa" separação entre essas duas formas. No entanto, a natureza artesanal da atividade impossibilita a intensa divisão entre trabalho manual e intelectual.

É possível perceber suas situações claras em relação a essa temática. Para os pescadores mais jovens, a aceitação dessa dissociação entre trabalho manual e intelectual é aceita com maior facilidade. Exemplo disso encontra-se nas observações de um dos pescadores entrevistados:

Em cada barco vão três a quatro pessoas. Cada um acaba se especializando em uma coisa. Tem gente que sabe prever o tempo, se vai chover ou não. Tem gente que é boa no lançamento da rede. Tem gente que só sabe pilotar o barco. Não dá para ser bom em tudo. Aliás, para dar menos trabalho é melhor definir o que cada um vai fazer em cima do barco. Assim, cada um tem sua responsabilidade (GPJ).

A divisão técnica que se desenvolve com o trabalho cooperado é aceita sem questionamentos, não havendo reflexão sobre suas possíveis consequências. Em prol da maior produtividade, organização e atribuição de responsabilidades, a aceitação é imediata. Foi possível verificar que os pescadores mais jovens não se importam com as consequências da divisão técnica do trabalho e de suas implicações em relação à divisão manual e intelectual.

Pela observação realizada na explicação de um grupo de pescadores mais velhos em relação aos procedimentos de pesca no barco, a divisão técnica do trabalho implica o estabelecimento de relações sociais definidas pelas relações de produção, conforme se observa na fala de um desses pescadores:

Esse pessoal mais novo tem força, mas nem sempre sabe onde colocar a rede. Às vezes, eles colocam quase um quilômetro de rede, mas o lugar não é bom. Outros, mais experientes, colocam duzentos metros e pegam a mesma quantidade de peixe. É por isso que nós velhos ainda sobrevivemos nesse ramo da pesca artesanal. A experiência e o tempo de mar nos possibilita saber pensar nas coisas antes de fazer. Eles ainda estão na fase de fazer mais para aprender a saber (PE).

A sociedade, em razão da necessidade cada vez maior de domínio da natureza, fomenta o alargamento dos mecanismos de divisão do trabalho. A especialização tornou-se regra inquestionável na esfera da vida social comum. Ela apresenta-se como condição essencial para que os homens invistam sobre a natureza, dominando-a cada vez mais. Assim, para os pescadores mais novos, a aceitação 
da divisão do trabalho, como já mencionado, é tida como natural. Apesar disso, eles reconhecem que o entendimento do todo é de suma importância para esse tipo de trabalho.

Nós sabemos que os mais velhos conseguem ter mais produtividade individual. Por isso mesmo que os barcos que levam um deles acabam voltando com mais pescados. Mas hoje existem poucos mestres (pescadores mais experientes). Para eles, a pesca é sua própria vida. Para a maioria dos mais jovens é apenas uma forma de ganhar a vida (GPJ).

Esse depoimento demonstra que trabalhar ocupando uma parte específica do parcelamento do trabalho é apenas mais uma atividade de trabalho para grande parte dos pescadores mais jovens. A rapidez e as transformações do mundo do trabalho tornam a atividade de aprender o todo da tarefa algo acessório. Há uma descrença pronunciada por ambas as partes:

Eu sei que meu filho vai acabar em outra profissão. Ele está fazendo faculdade e agora está trabalhando com o comércio de peixe. Dá mais dinheiro. Ele não terá a mesma vida que eu. Daqui a dois ou três anos, talvez ele nem suba mais no barco para pescar. Ele não vai passar seus quarenta e cinco anos indo e voltando do mar. Por isso, eu não faço questão que ele aprenda tudo que eu aprendi no $\operatorname{mar}(\mathrm{PE})$.

Os mais velhos conseguiram criar bem suas famílias indo e voltando do mar. Mas nós sabemos que não conseguiremos isso. Daqui a dez anos, acho que nem vai ter mais espaço para a pesca artesanal. Os barcos grandes acabam com os peixes e são muito mais produtivos. Aprender tudo não vale a pena, o trabalho na pesca artesanal não terá futuro. Muitos já estão fazendo outras coisas paralelas. Alguns são pintores, outros têm restaurantes. E assim vai, até acabar tudo (GPJ).

Há uma descrença quanto ao futuro da pesca artesanal, por isso, não é motivadora a ideia de aprender todo o processo produtivo da pesca. A divisão do trabalho, nesse sentido, acaba sendo a opção mais viável para os pescadores mais jovens, porque para eles o conhecimento de todo o ofício não será útil em um futuro próximo.

Essa perspectiva cria condições mais concretas para a instrumentalização dos pescadores mais jovens. O trabalho e seus parcelamentos são cada vez mais técnicos e instrumentais, com o objetivo único de garantir produtividade. A falta 
de expectativas e o fim da crença na pesca tornam os pescadores mais suscetíveis a aceitar a condição de meios para realização da produtividade. $\mathrm{O}$ abandono afetivo dos pescadores em relação à sua atividade coloca-os na condição de instrumentos. Apesar dessa tendência, é possível perceber que há contradições, sobretudo quando o saudosismo provocado pelos mais velhos vem à tona:

Se eu soubesse que a pesca artesanal iria garantir uma vida boa para mim eu continuaria nela. Eu vejo o meu tio contando suas histórias e vejo como ele é feliz sendo pescador. Mas fazer o quê? Nós temos necessidades que só a pesca não garantirá que elas sejam realizadas. Esse tempo do meu tio acabou. Para ele, que é mais velho, a pesca é sua vida, para nós é apenas um momento passageiro (GPJ).

\subsection{TECNOLOGIA}

O termo tecnologia tem sido usado para identificar máquinas ou utilização de novas máquinas no processo produtivo. Como já exposto em outra oportunidade (FARIA, I992), essa concepção é evidentemente restrita, o que acaba prejudicando a interpretação e análise dos problemas relativos aos efeitos da tecnologia sobre o processo de trabalho. A tecnologia deve ser entendida como o conjunto de conhecimentos aplicados a determinado tipo de atividade. A tecnologia empregada em um processo de produção compreende as técnicas e o uso de técnicas que interferem na organização do trabalho, de maneira a modificá-lo, organizá-lo, racionalizá-lo, sejam tais técnicas de origem física (máquinas, peças e componentes), sejam de origem gerencial (FARIA, I992).

A utilização de novas tecnologias no processo produtivo é irreversível, na medida em que decorre da superação das contradições inerentes ao próprio processo de acumulação. Trata-se de uma exigência da dinâmica capitalista, cuja base é a valorização do capital. Pesquisas que tratam desse tema de forma geral têm ficado restritas ao exame das tecnologias materiais ou físicas (máquinas, equipamentos etc.). É preciso indicar que existem problemas que afetam a vida do trabalho que estão além do seu aspecto físico imediato. A tecnologia não se constitui apenas de sua parte material, mas também da gestão do processo de trabalho (FARIA, I992).

A cada nova forma de divisão do trabalho, sobretudo orientada pela incorporação de novas tecnologias físicas, há uma reorganização das relações sociais de trabalho. Essa nova configuração afeta não só o processo de trabalho, mas as relações entre os indivíduos, entre estes e o mundo concreto e as formas abstratas da vida social (FARIA, 2004). O impacto da tecnologia física afeta de duas formas 
a pesca artesanal: I. como reorganização do trabalho pelos próprios pescadores artesanais; 2. como ameaça quando os concorrentes se utilizam de equipamentos modernos para a pesca em grande escala.

As duas situações foram amplamente abordadas tanto pelos pescadores mais experientes como pelos mais jovens. Todavia, há divergências de entendimentos, sobretudo no item relacionado à reorganização do trabalho. Para os mais experientes, o emprego da tecnologia física é um instrumento que auxilia e facilita as atividades da pesca artesanal.

Hoje se pesca em barcos movidos a motores. Quem não quer ter um motor Yamaha? Em pouco tempo, você está em alto-mar. Mas só isso não é suficiente. Tem que saber como incorporar esses avanços na sua atividade. Hoje se fala tanto nos sonares, que eles ajudam saber onde tem cardumes de peixes. Mas quem garante que o peixe vai cair na rede? $\mathrm{Na}$ pesca próxima da praia, pega mais quem tem mais experiência! (PE).

Apesar desse entendimento, eles têm noção de que a tecnologia auxilia em casos específicos:

O sonar ajuda nos casos de pesca em alto-mar. Esses grandes pesqueiros vão direto ao cardume. Só que o equipamento não é capaz de diferenciar os tipos de peixes que estão lá embaixo. Nós não sabemos, mas a máquina também não (PE).

Apesar da incorporação de tecnologias físicas modernas, sobretudo em relação aos motores dos barcos e às novas malhas para as redes, a pesca artesanal vive em razão da utilização de instrumentos rudimentares. Entre os pescadores mais experientes, pelo menos cinco dos seis entrevistados disseram que preferem ir para o mar e pescar sem auxílio de equipamentos de navegação, motores possantes ou redes de malhas finas. Essas informações direcionaram para a necessidade de saber o por que da não utilização das novas tecnologias. Algumas respostas esclarecem parte do questionamento:

Vou te dizer uma coisa. Eu sei que no futuro a pesca será bem diferente. Mas o pescador tradicional existe desde a época de Jesus. Claro, quem quer ganhar dinheiro não pode viver nessa forma de trabalho. Mas ainda dá para defender sua família. Tem muito pescador jovem que leva no barco essas novas máquinas, mas também sei que muitos deles voltam com menos peixe do que os velhos da pesca. Tem conhecimento que máquina nenhuma consegue pegar! (PE). 
De fato, analisando a tábua de resultados de pesca por barco, fixada no mercado de peixe da cidade, a produtividade média dos mais experientes é $5 \%$ superior. Contudo, o controle de produtividade realizado não pode ser considerado certo e estatístico em razão da descontinuidade do controle e da falta de critérios para os diversos tipos de pescados. Esse fato pode ser comprovado porque alguns peixes têm mais valor comercial do que outros, da mesma forma que o camarão é avaliado não só pelo peso total da pesca, mas também pelo tamanho médio dos capturados.

Outro pescador experiente levou a resposta para outra direção:

Para mim, que daqui a pouco não vou conseguir nem subir no barco, não adianta nada querer aprender com essas novas máquinas. Tem umas que têm muitos números. Não sou bom na matemática. Hoje eu saio para o mar e pego peixe para viver. Está bom demais. Pescar para um velho do mar é a mesma coisa que viajar para um velho da estrada. É a vida! É a nossa história! (PE).

Diante da não necessidade de manter a produtividade em alta, da relativa "facilidade" de manter a renda com a atividade e da não capacidade de lidar com as novas tecnologias físicas, os pescadores mais experientes tendem a entender essa tecnologia como algo sem demasiada importância. Além disso, é fato que as tecnologias físicas empregadas na pesca artesanal, na maioria das vezes, são acessíveis e referem-se, basicamente, a motores e materiais das redes.

Para os pescadores mais jovens, a necessidade de pensar na subsistência da família leva-os a olhar a tecnologia física como meio para aumento da produtividade e de melhorias de ganhos. As respostas dos mais jovens enfatizaram tanto quantitativa como qualitativamente dois aspectos importantes: a utilização da tecnologia pelos concorrentes diretos e indiretos e a dificuldade de aquisição da tecnologia para a melhoria da sua atividade.

A tecnologia física em posse dos concorrentes diretos (basicamente as embarcações médias e os barcos de pesca industrial) e indiretos (piscicultura e cativeiros de criação de camarão) provoca, segundo as afirmações dos pescadores mais jovens, a queda de produção dos pescados:

É difícil concorrer com esses grandes barcos de pesca que vêm do Rio Grande do Sul ou de Santa Catarina. Eles têm equipamentos que dão autonomia de vinte dias, um mês no mar. Eles pescam com sonares e suas malhas [redes de pesca] levam tudo. Principalmente, quando eles fazem o arrasto noturno. De manhã, não sobra nada (GPJ). 
O entendimento é claro e conclusivo para os pescadores. A tecnologia física que eles incorporam nas suas atividades é modesta e, comparada às incorporadas aos grandes barcos, limitada para o aumento da produtividade. Os pescadores mais jovens, tomados pela lógica da mercadoria, da produtividade, pensam em termos quantitativos, sobretudo por ter internalizado as regras do sistema de recompensas do capitalismo. A visão dos pescadores jovens está muito mais atrelada ao contexto do capitalismo, apesar de sua atividade ser de natureza artesanal.

\subsection{FORMAS DE GESTÃO DO TRABALHO}

Organização, tal como atualmente é empregado, é um conceito sociológico e refere-se à estrutura formal ou regular de elementos que constituem uma entidade, a qual serve à realização de ações de interesse econômico, jurídico-político, social, cultural e ideológico. Morfologicamente, o conceito de organização tem sido empregado indistintamente não apenas no que se refere à estrutura de elementos que constituem uma entidade, mas igualmente para referenciar processos, práticas ou formas de ação. Assim, pode-se afirmar que existem, ontologicamente, dois tipos básicos de organização: I. as reais ou categóricas, que, na sociologia, são denominadas organizações formais; 2 . as políticas ou de pertença. As formais são aquelas unidades complexas que se estruturam de acordo com uma finalidade (econômica, política, cultural etc.). A toda organização corresponde uma forma de gestão (FARIA, 2004). Nesta pesquisa, a organização deve ser entendida em ambos os sentidos: em seu sentido formal, quando sua materialidade se refere a uma embarcação; como forma política de ação coletiva, quando sua materialidade se refere à luta dos pescadores por reconhecimento social e retibuição econômica.

Antes de descrever a forma de gestão predominante na comunidade de pescadores artesãos, é necessário recorrer às experiências históricas concretas das formas de gestão. Em uma análise anterior (FARIA, 2009), verificou-se que o controle sobre os elementos constitutivos da gestão do trabalho aparece das mais diferentes formas. O Quadro 2 sintetiza as formas de gestão e de organização. Esse esboço geral indica os graus de controle, pelo conjunto dos trabalhadores, dos elementos objetivos e subjetivos da gestão do processo de trabalho e, portanto, sua capacidade de definir e realizar seus interesses objetivos e subjetivos específicos. Vale dizer, indica o poder do conjunto dos produtores (FARIA, 2009). 
QUADRO 2

MODELOS DE FORMAS E MODOS DE GESTÃO

\begin{tabular}{|c|c|c|c|c|c|}
\hline $\begin{array}{l}\text { FORMAS DE } \\
\text { GESTÃO/ } \\
\text { MODOS }\end{array}$ & HETEROGESTÃO & $\begin{array}{l}\text { GESTÃO } \\
\text { PARTICIPATIVA }\end{array}$ & COGESTÃO & $\begin{array}{l}\text { GESTÃO } \\
\text { COOPERATIVA }\end{array}$ & AUTOGESTÃO \\
\hline $\begin{array}{l}\text { Modos } \\
\text { Específicos }\end{array}$ & $\begin{array}{l}\text { (i) Absoluta } \\
\text { (monárquica; } \\
\text { imperial); } \\
\text { (ii) } \\
\text { Oligárquica; } \\
\text { (iii) } \\
\text { Burocrática } \\
\text { Formal (que } \\
\text { se encontra } \\
\text { em vários } \\
\text { cruzamentos } \\
\text { da matriz). }\end{array}$ & $\begin{array}{l}\text { (i) Restrita } \\
\text { (apenas } \\
\text { no local de } \\
\text { trabalho); } \\
\text { (ii) Consultiva } \\
\text { Pontual; } \\
\text { (iii) Consultiva } \\
\text { Representativa; } \\
\text { (iv) Expandida } \\
\text { (Organizações } \\
\text { de Economia } \\
\text { Solidária); } \\
\text { (v) Popular } \\
\text { ou Coletiva } \\
\text { (Conselhos de } \\
\text { Trabalhadores } \\
\text { ou Comissões } \\
\text { de Fábrica). }\end{array}$ & $\begin{array}{l}\text { (i) Relativa } \\
\text { (alguma par- } \\
\text { ticipação dos } \\
\text { produtores } \\
\text { em conselhos } \\
\text { superiores); } \\
\text { (ii) Partilhada } \\
\text { (participação } \\
\text { formal e legal } \\
\text { dos produto- } \\
\text { res nos con- } \\
\text { selhos supe- } \\
\text { riores a partir } \\
\text { de critérios } \\
\text { de represen- } \\
\text { tatividade). }\end{array}$ & $\begin{array}{l}\text { (i) Limitada } \\
\text { (organizações } \\
\text { cooperativas } \\
\text { de produção, } \\
\text { de crédito, de } \\
\text { serviços, que } \\
\text { operam como } \\
\text { empresas de } \\
\text { sócios); } \\
\text { (ii) Coletivista } \\
\text { de Produtores } \\
\text { Associados } \\
\text { (lugoslávia); } \\
\text { (iii) } \\
\text { Comunitária } \\
\text { de Trabalho } \\
\text { Associado } \\
\text { (Kibutz). }\end{array}$ & $\begin{array}{l}\text { (i) Anárquica; (ii) } \\
\text { Parcial ou } \\
\text { Coletivista } \\
\text { (autogestão ao } \\
\text { nível de unidades } \\
\text { produtivas ou } \\
\text { Organizações } \\
\text { Solidárias de } \\
\text { Produção, sob } \\
\text { uma gestão } \\
\text { coletivista de } \\
\text { trabalho e com } \\
\text { restrições nas } \\
\text { relações com } \\
\text { o ambiente } \\
\text { externo); } \\
\text { (iii) Plena ou } \\
\text { Social. }\end{array}$ \\
\hline
\end{tabular}

Fonte: Faria (2009, p. 38).

O tipo predominante de organização produtiva é o formal ou estável, porque se baseia em normas, regulamentos e divisão do trabalho. Cada barco pode ser classificado como uma organização, pois possui um conjunto de normas de trabalho e segurança, além de obedecer à legislação sobre navegação, pois os pescadores e os respectivos barcos de pesca devem se submeter às formalizações portuárias e atender às exigências legais para poder operar. Todavia, diferentemente das organizações capitalistas, nos barcos há flexibilidade, pois muitas normas ou regras que determinam os procedimentos dos pescadores nem sempre são formalizadas ou rígidas. Outra característica importante é que, mesmo havendo divisão do trabalho, os pescadores - em média dois ou três por barco - sabem operar todas as etapas de execução do processo da pesca. A divisão do trabalho, nesse sentido, serve para manter uma racionalização para ganho de produtividade. 
Duas são as formas de gestão predominantes. Para os barcos dos pescadores mais experientes, com seus familiares ou pessoas de vínculos sociais antigos, o modelo predominante é o da gestão participativa grupal. Apesar de haver uma hierarquia estabelecida motivada pelos vínculos familiares, é possível perceber que todos participam do processo de decisão. Dos pescadores mais experientes entrevistados, todos apontam essa tendência, fato que pode ser comprovado e resumido nas manifestações:

No barco trabalham eu, meu filho e meu genro. Apesar de eu ser o mais antigo neste trabalho, todos podem dizer o que pensam. Fica fácil, porque nós temos mais liberdade. Mas nem sempre isso acontece porque, mesmo sendo da família, as coisas podem não dar certo. No meu caso e dos meus compadres mais velhos, não temos do que reclamar porque o negócio anda (PE).

É engraçado que apesar das brigas que temos com nossos pais, as coisas se ajeitam. Ele cede um pouco e eu também. [...] É melhor trabalhar assim. Se eu tivesse um patrão não poderia dizer a metade do que digo para o meu pai (GPJ).

Já entre os barcos com pescadores mais jovens, a forma predominante é a heterogestão relativa. O proprietário da embarcação contrata a mão de obra e tem o poder de decisão. Quem administra, dessa forma, é o dono da embarcação e dos instrumentos de trabalho. Observa-se, contudo, que o poder de decisão não chega a ser totalmente centralizado nas mãos do proprietário. O motivo é simples e direto: nem sempre o proprietário parte para o mar. Assim, os outros integrantes exercem certa autonomia em relação a algumas decisões. Há outro fator importante. Como a atividade de pesca apresenta certa imprevisibilidade de produção, nem sempre é possível cobrar resultados. A racionalização da produtividade, dessa forma, cede certo espaço para a imprevisibilidade.

Não dá para dizer que você sai para o mar e vai voltar cheio de peixe. O mar não é uma prateleira de pequenas peças para montar um motor, por exemplo. Tem dia que não adianta, o peixe não vem. Só quem está no mar entende isso (GPJ).

Observa-se, portanto, que as formas de gestão são diferenciadas. Essa informação implica vínculos diferentes com o trabalho. 


\subsection{MERCADORIA}

Não se pode tratar da mercadoria sem recorrer a Marx. Logo na Seção I do Capítulo I, Marx (i983a, p. 35) afirma que "a riqueza das sociedades em que domina o modo de produção capitalista apresenta-se como uma 'imensa acumulação de mercadorias'”. A mercadoria, para Marx, é um objeto exterior que, pelas suas propriedades, satisfaz necessidades humanas de qualquer espécie, independentemente de como essas são satisfeitas, se como meio de subsistência ou como meio de produção. Toda mercadoria, continua Marx (I983a, p. 35),

[...] pode ser consideradas sob um duplo ponto de vista: o da qualidade e o da quantidade. Cada uma delas é um conjunto de propriedades diversas, podendo, por conseguinte, ser útil sob diferentes aspectos [...]. A utilidade de uma coisa transforma essa coisa num valor-de-uso. Mas esta utilidade nada tem de vago e de indeciso. Sendo determinada pelas propriedades do corpo da mercadoria, não existe sem ele [...]. Os valores-de-uso só se realizam pelo uso ou pelo consumo. Constituem o conteúdo material da riqueza, qualquer que seja a forma social dessa riqueza. Na sociedade [capitalista] são, ao mesmo tempo, os suportes materiais do valor-de-troca [...]. O valor-de-troca surge, antes de tudo, como a relação quantitativa, a proporção em que valores-de-uso de espécie diferente se trocam entre si, relação que varia constantemente com o tempo e o lugar.

O caráter fetichista da mercadoria encontra-se exatamente nela mesma. Para Marx (I983a, p. 94), o caráter misterioso da forma-mercadoria consiste, portanto, simplesmente em que ela apresenta aos homens as características sociais do seu próprio trabalho como se fossem características objetivas dos próprios produtos do trabalho, como se fossem propriedades sociais inerentes a essas coisas; e, portanto, reflete também a relação social dos produtores com o trabalho global como se fosse uma relação social de coisas existentes para além deles. É por esse quiproquó que esses produtos se convertem em mercadorias, coisas a um tempo sensíveis e suprassensíveis (isto, é, coisas sociais).

Nesse processo, os sujeitos tornam-se reificados porque sua consciência é coisificada. "A reificação é definida pelo aparecimento na vida social de processos econômicos enquanto fenômenos autônomos e, por isso, puramente quantitativos" (MATOS, I995, p. I66). No caso em estudo, as mercadorias praticamente não possuem trabalho humano objetivado além do ato da pesca. O Quadro 3 indica as mercadorias de que se trata aqui. 


\section{QUADRO 3}

PESCADOS E SEUS RESPECTIVOS VALORES COMERCIAIS

\begin{tabular}{|c|c|}
\hline TIPOS DE MERCADORIAS & MERCADORIAS \\
\hline $\begin{array}{l}\text { Pescados de alto valor } \\
\text { comercial }\end{array}$ & $\begin{array}{l}\text { Camarão sete-barbas (Xiphopenaeus kroyeri1), camarão } \\
\text { branco (Penaeus shmitti1), camarão pistola (Penaeusshmitti } \\
\text { e Farfantepenaeus spp), linguado (Paralichthys spp), robalo } \\
\text { (Centropomus spp). }\end{array}$ \\
\hline $\begin{array}{l}\text { Pescados de médio valor } \\
\text { comercial }\end{array}$ & $\begin{array}{l}\text { Betaras (Menticirrhusamericanus e M. littoralis), pescadas } \\
\text { (Cynoscion spp), corvina (Micropogonias furnieri), cavala } \\
\text { (Scomberomorus sp), salteira (Oligoplites sp), anchova } \\
\text { (Pomato mussaltator), cação (várias famílias de Squaliformes), } \\
\text { paru (Chaetodipterus faber) e tainha (Mugil spp), badejo } \\
\text { (Mycteroperca sp), garoupa (Epinephelus sp) e caranha } \\
\text { (Haemulidae). }\end{array}$ \\
\hline $\begin{array}{l}\text { Pescados de baixo valor } \\
\text { comercial }\end{array}$ & $\begin{array}{l}\text { Manjuba (Engraulidae), sardinha (Clupeidae), Gerreidae, } \\
\text { Carangidae, alguns Pleuronectiformes, alguns Sciaenidae e } \\
\text { outros. }\end{array}$ \\
\hline
\end{tabular}

Fonte: Informações dos pescadores e dos comerciantes do mercado de peixe. Denominações técnicas inseridas pelos autores.

Duas situações foram verificadas nas entrevistas com os pescadores. A primeira é manifestada especialmente pelos pescadores mais velhos e expressa sinteticamente por um deles:

O pescado não é um produto. É a história da pesca, do nascer do dia até a entrega dele para a venda. Eu já vi de tudo nesse mar. Antigamente, a gente pegava peixe de sete, oito, quinze quilos. Hoje não tem mais isso. Essa diferença nos pesos é porque as pessoas não pescam mais para manter a família. Eles pescam para ganhar dinheiro (PE).

Essa manifestação deixa evidenciado não apenas o processo completo de trabalho, mas sua alteração decorrente dos interesses do capital.

A segunda situação é, ao mesmo tempo, a mesma e contrária a ela, porque se tratam de dois discursos sob pontos de vista diferentes de um mesmo problema, que é a lógica do sistema de capital invadindo o que antes era economia de subsistência ou artesanal. De fato, diferentemente do discurso dos pescadores mais velhos, os pescadores mais jovens têm outra concepção sobre o pescado capturado: 
Todo mundo sabe que se não preservar agora, no futuro será difícil a pesca da maneira como fazemos. Mas se nós não capturamos os peixes, os grandes barcos fazem por nós. Garanto que a grande maioria prefere um churrasco a um peixe. A maioria até gosta do seu trabalho, mas se tivesse chance de fazer outra coisa, faria. Tem gente que vê o peixe como um número. Esse número é melhor se você pegar mais camarão e linguado do que cação e tainha. É assim, quem pega mais e melhor chora menos na praia (GPJ).

O avanço da reificação entre os pescadores mais jovens corresponde à observação de Horkheimer (2000, p. I32) de que

[...] quanto mais intensa é a preocupação do indivíduo com o poder sobre as coisas, mais as coisas o dominarão, mais lhe faltarão os traços individuais genuínos, e mais a sua mente se transformará num autômato da razão formalizadora.

Ainda que os discursos sejam diferentes, os pescadores mais experientes também entendem que os pescados são mercadorias, que têm valor de troca que corresponde a um equivalente de ascensão social:

Eu gosto de pescar, mas também estou preocupado em pegar bastante peixe para poder dar um bom estudo para meus filhos. Digo para eles que eles devem respeitar o mar, porque é de lá que vem o que eles comem e as regalias deles (PE).

Em ambas as situações,

A mercadoria é misteriosa simplesmente por encobrir as características sociais do próprio trabalho dos homens, apresentando-as como características materiais e propriedades sociais inerentes aos produtos do trabalho; por ocultar, portanto, a relação social entre os trabalhos individuais dos produtores e o trabalho total, ao refleti-la como relação social existente, à margem deles, entre os produtos do seu próprio trabalho (MARX; ENGELS, 200I, p. 94).

\subsection{PROPRIEDADE PRIVADA}

A mercadoria - os pescados - tem para o pescador um valor comercial (valor de troca) e outro como resultado do trabalho visando à subsistência (valor de uso). Como se sabe desde Marx (1983b), o valor de troca se constitui quando a mercadoria não tem valor de uso para seu produtor, mas tem para seu comprador. 
No caso estudado, a apropriação do pescado se dá como valor de uso para seu produtor, que o consome em sua unidade familiar, e valor de troca para o excedente do consumo. O que chama a atenção, nesse caso, é a diferença qualitativa existente entre a mercadoria "pescado" destinada a valor de uso e a destinada a valor de troca. O pescado oferecido ao comprador no mercado é de melhor qualidade se comparado ao utilizado na alimentação dos pescadores e de suas famílias. Isso acontece, como já indica Marx (1983b), porque, para haver valor de troca, é preciso haver valor de uso para o comprador. Nesse sentido, o pescador precisa oferecer a melhor mercadoria para a troca.

Além disso, também se percebe distinção quando se trata da forma de gestão. Entre os mais experientes - em que a forma predominante é a gestão participativa grupal -, a propriedade dos meios de produção (embarcações, redes, equipamentos e demais) tem menor importância ou define menos as relações estabelecidas entre os pescadores. Além disso, a distribuição dos resultados obtidos entre os pescadores é dividida, se não igualitariamente, pelo menos em proporções mais equivalentes às necessidades familiares e à propriedade dos meios de produção.

A predominância da relação familiar no processo produtivo não suplanta as decisões baseadas na propriedade dos meios de produção. Porém, diferentemente de um empreendimento capitalista, o proprietário desses meios faz um "cálculo econômico" que leva em conta os "custos" (combustível, manutenção, depreciação, pagamento de licença etc.) para fazer a divisão mais adequada dos resultados.

No caso dos pescadores mais jovens, a heterogestão relativa intensifica as diferenças entre os produtores. A definição clara dos proprietários dos meios de produção é mais explícita, intensificando a divisão entre os indivíduos por resultado da produção - a quantidade de pescados. A propriedade das embarcações, da licença de pesca, dos equipamentos e demais, praticamente define a relação hierárquica entre os pescadores. As relações são mais impessoais e o discurso consolida a relação entre capital e trabalho:

Quem é dono do barco, da licença, manda. Quem não é, trabalha por jornada ou por produtividade. Nesse caso, o que vale é a quantidade de peixe que você traz para o mercado. Chegando à terra, vem o dono do barco e define quanto a gente vai ganhar. Se a pescada foi boa a gente ganha mais, se não foi tem que ir para o mar tentar novamente. Assim, a gente continua vivendo (PE).

Como observam Marx e Engels (200I, p. 97),

[...] é, porém, essa forma acabada do mundo das mercadorias, a forma dinheiro, que realmente dissimula o caráter social dos trabalhos privados e, em consequência, as relações sociais entre os produtores particulares, ao invés de pô-las em evidência. 


\subsection{FETICHE DA MERCADORIA}

Lukács (1969, p. 96) procura compreender os problemas fundamentais da objetividade do trabalho e do comportamento subjetivo por meio da racionalização crescente da sociedade. Essa característica é uma crítica ao caráter objetivo do trabalho, em que, com a racionalização e a mecanização crescentes do processo de trabalho, a atividade do trabalhador vai perdendo cada vez mais intensamente seu próprio caráter de atividade, para converter-se paulatinamente em uma atitude contemplativa.

Somada à diferença qualitativa entre a mercadoria como meio de intercâmbio social entre os indivíduos e comércio material como meio universal de configuração social, a reificação tem influência negativa na estrutura e na articulação que organiza a sociedade. Repercute também nas relações sociais, pois estas são mediadas pelas leis do comércio e das trocas, orientando e disciplinando, inclusive, as trocas provenientes dos aspectos subjetivos da condição humana. Isso porque "o homem se confronta com sua própria atividade, com seu próprio trabalho, como com algo objetivo, independente dele, como algo o domina a ele mesmo por obra de leis alheias ao humano" (LUKÁCS, I969, p. 93).

A concepção marxista de Lukács pode ser identificada na relação entre os pescadores de diferentes formas, conforme os depoimentos:

O trabalho é legal, mas confesso que nem sempre sinto prazer no que faço. O que interessa para mim, muitas vezes, é pegar o máximo de pescados possível e pegar meu dinheiro. Tem época que nem como peixe de tão enjoado que fico em olhar para eles (GPJ).

Acho legal estar com outras pessoas trabalhando, mas tem dia que vamos e voltamos do mar sem trocar uma palavra entre nós. É como se fôssemos máquinas. [...] percebo que os mais velhos sempre estão contando suas histórias. Entre os mais jovens, o que nós queremos é falar de carro, futebol, mulherada. Tenho certeza de que os velhos são felizes no trabalho, os mais novos gostam, mas não amam como eles! (GPJ).

O trabalho alienado é, de fato, percebido com intensidade entre os mais jovens. Entre os mais experientes, a percepção é outra. Várias são as justificativas apontadas pelos próprios trabalhadores por meio da sua autopercepção: 
Nós gostamos do mar. Tem algo de misterioso nele. Eu entro em transe. Não sei o que faria se não pudesse mais pescar. A vida no mar é uma integração com a natureza. Tudo isso vai acabar um dia. Eu conheço um pintor que sente o mesmo em relação ao seu trabalho. Eu fico arrepiado todas as vezes que acordo e vejo aquele mundão de água. O mar é minha vida (PE).

Eu tenho um irmão que é caminhoneiro. Ele teve diabetes e perdeu parte da visão. Agora, que ele não pode mais viajar, o mundo dele acabou. Ele vive triste, só o vejo alegre quando ele conta os “causos" das viagens. Imagino quando eu não puder ir mais para o mar. Vai ser difícil. Eu sei que uma parte da gente morre quando deixamos de fazer o que gostamos (PE).

A gente se reúne na praia para grelhar um linguado e conversar, jogar um baralho. Os mais jovens querem é beber. Aliás, é um problema grave o da bebida entre os mais jovens. Muitos são infelizes no trabalho, eu sei disso (PE).

A relação entre o produtor e o produto do seu trabalho também é diferente entre os pescadores mais jovens e os mais experientes. Os primeiros concebem o resultado da pesca como sinônimo de sucesso, enquanto os mais experientes, como resultado de um dia de trabalho prazeroso. A relação com os pescados também é diferente entre esses grupos. A impressão que se tem é a de que os mais jovens sentem certo desprezo pelo que conseguiram pescar, e para os mais experientes é o resultado de um dia de prazer e sucesso no trabalho.

Para mim um peixe é um peixe, somente isso. Não sei como meu pai conseguiu viver tantos anos fazendo a mesma coisa. Pior, ele adora comer peixe. Gosta de uma feijoadinha também, mas tem que ter peixe com pirão pelo menos umas três vezes por semana. Eu estou enjoado (GPJ).

Como afirma Lukács (I969, p. Ioo),

Como já mencionado, o trabalhador tem de representar-se como um "detentor" da sua força de trabalho como mercadoria. Sua posição específica encontra-se em que a força de trabalho é a única coisa que tem. E o típico de seu destino para a estrutura da sociedade é que essa auto-objetivação, a conversão de um papel humano em mercadoria, revela mais claramente o caráter desumanizado e desumanizador da relação mercantil. comercial. 


\section{CONCLUSÃO: O ARTESÃO dO MAR NAS REDES DA REIFICAÇÃO}

Em Dialética negativa, Adorno (I975) afirma que somente aqueles não completamente moldados pelo mundo administrado podem resistir ao processo de reificação. Esta pesquisa mostra que, apesar do processo crescente de racionalização da produção capitalista, ainda há espaços de trabalho em que reificação não se instalou tal como no modelo capitalista de produção de mercadorias. É essa a realidade que expressam os pescadores mais experientes. Não se trata de uma forma de resistência com base em uma consciência de classe ou mesmo em uma consciência crítica do lugar que eles ocupam no sistema de produção capitalista. $\mathrm{O}$ trabalho realizado pelos pescadores mais experientes foge à regra do trabalho alienado, pois eles trabalham para si e não para alienar o produto de seu trabalho para outro.

É possível, assim, definir uma hipótese, que é bastante provável, para entender essa situação: a pesca artesanal é uma atividade secundária, subordinada, periférica aos interesses da acumulação capitalista e, por isso, não é objeto de sua exploração.

A reificação, entre os pescadores mais jovens, dá-se pelo conjunto dos elementos (relacionados ao trabalho e à mercadoria) responsáveis pela transformação do sujeito em instrumento do capital. É a transformação da condição de produtor para a de mercadoria, com todas as suas propriedades.

Em relação ao trabalho, sua organização, sua constituição formal e divisão são elementos importantes para a definição do trabalho alienado. Praticantes de uma forma de gestão participativa, os pescadores mais experientes, na sua origem, estão menos suscetíveis à reificação. Todavia, a tendência hegemônica do modo de produção capitalista e do sistema de capital manifesta-se não somente pela organização do trabalho, mas também pela ideologia materializada na consciência dos indivíduos, e impõe aos pescadores mais experientes a certeza de que a pesca artesanal está em vias de chegar ao seu fim.

A tecnologia física é outro elemento que contribui para intensificar a reificação. Se, por um lado, os pescadores mais experientes podem ser considerados mais produtivos, por outro, tanto eles quanto os mais jovens conhecem "o poder das grandes embarcações”. Não é possível assegurar que a pesca artesanal vai acabar e que não haja solução para essa provável ocorrência. Porém, considerando a perspectiva histórica do desenvolvimento das forças produtivas, a atividade de pesca artesanal, como uma das mais antigas, pode resistir ao modo capitalista de produção. O mesmo não se pode dizer da atividade de pesca. 
De fato, as modificações que a pesca artesanal experimentou ao longo de sua existência histórica são pequenas se comparadas ao sistema capitalista de produção de mercadorias. A pesca artesanal, assim, pode não vir a ser transformada pelo modo de produção capitalista. Contudo, atividade pesqueira encontra-se cada vez mais sob o comando do capital. A pesca artesanal tende a ser cada vez menos importante como atividade, inclusive de sobrevivência, exatamente porque a atividade da pesca encontra-se apropriada pelo sistema de capital, com avanços tecnológicos físicos e de gestão.

A relação da reificação com a mercadoria é outro ponto importante. O produto do trabalho é encarado de forma diferente entre os pescadores mais experientes e os mais jovens. Para os primeiros, constitui-se em resultado do envolvimento total do seu trabalho; representa a satisfação e a relação com o domínio total do trabalho e não o parcelamento do trabalhador no processo de produção; está incorporado na personalização própria de todo trabalhador que se realiza, na maioria das vezes, com seu trabalho ao mesmo tempo que o domina por completo. O trabalho, nesses casos, é a própria vida do trabalhador.

Para os mais jovens, a mercadoria manifesta apenas a recompensa pelo dia de produção. O pescador não se sente ele mesmo um indivíduo completo, senão um instrumento para o acúmulo da riqueza dos proprietários dos meios de produção. A divisão do trabalho facilita o trabalho imediato, mas, ao mesmo tempo, desumaniza-o, porque torna o pescador instrumento do processo de trabalho. Nem mesmo seu esforço físico lhe pertence. A realização é externa ao pescador.

A pesquisa com os pescadores identificou dois grupos distintos: os pescadores mais experientes, que aos poucos são desalojados da ocupação, até mesmo ou especialmente pela idade, e os pescadores mais jovens, já submetidos à lógica do sistema de produção capitalista.

A observação em relação aos mais experientes serve como exemplo de que o trabalho é uma forma de realização, ainda que, dialeticamente, contenha em si e para si contradições e sofrimentos. A observação em relação aos mais jovens mostra que, nesse caso, não predomina no trabalho o prazer e a realização, mas o sofrimento inerente ao processo de reificação que o trabalho alienado impõe. Isso não significa que esse trabalho seja destituído de prazer e realização, mas que estes não são os fatores dominantes. O trabalho é e deve ser ao mesmo tempo o momento da realização e do sofrimento, quaisquer que sejam suas condições e formas, como a história do trabalho tem constatado. Mas a distância entre realização e sofrimento pode ser maior ou menor de acordo com o processo de divisão e de gestão do trabalho, de sua relação com as tecnologias, da propriedade e posse dos meios de produção e da relação entre produtor, proprietário, vendedor e comprador da mercadoria. 


\section{THE MANAGEMENT AND REIFICATION OF MEN OF THE SEA}

\section{ABSTRACT}

A man is as man because he is able to produce his means of survival, among which work plays a central role in the constitution of society. It is through it that men "dominate" nature and place themselves in the position of lords before it. The fishing activity may be considered "secondary" in the interests of capital accumulation and it is precisely the reason why the study of the community of fishermen from the town of Matinhos, Paraná State, constitutes one of the prime locations to see how work (comprising the division of labor, technology and management form) and goods (comprising private property and the commodity fetish) constitute the multiple determinations of the real and are related to the process of social reification. The aim of this work is to understand the process of reification of traditional fishermen, the analysis of the categories defined as multiple determinations of the real, in view of its economic integration and social exclusion in the system of capital. The theoretical basis of the work consists of authors such as Marx, Lukács, Adorno, Faria, Horkheimer, Meszáros, and others. This is a qualitative research carried out in a community of fishermen. It was possible to verify that the reification among the younger fishermen takes the set of elements (related to labor and goods) responsible for the transformation of the subject into an instrument of capital. It is the transformation of the condition of the producer into the commodity, with all its properties. Reification is also related to the alienated labor and that, despite the hegemonic tendency of the capitalist system of production, it is possible to identify a resistance in relation to this process of reification. In short, there would be a reification which is related to the alienated labor and, despite the hegemonic tendency of the capitalist system of production, it is possible to identify a resistance against this process of reification.

\section{KEYWORDS}

Management; Artisanal fisheries; Reification; Alienation; Work. 


\section{GESTIÓN Y REIFICACIÓN DE LOS HOMBRES DEL MAR}

\section{RESUMEN}

El hombre es hombre porque es capaz de producir sus medios de supervivencia, entre los cuales, el trabajo ocupa un lugar central en la constitución de la sociedad. Es a través de lo que los hombres "dominan" la naturaleza y se ponen en la posición de los Lores antes que ella. La actividad pesquera se puede considerar una "secundaria" en aras de la acumulación de capital y es precisamente por qué el estudio de la comunidad de pescadores de la ciudad Matinhos, el estado del Paraná, parece una de las mejores ubicaciones para ver cómo trabajo (que incluye la división del trabajo, la tecnología y la forma de gestión) y bienes (que comprende la propiedad privada y el fetiche de los productos básicos) constituyen las determinaciones múltiples de lo real y están relacionados con el proceso social de reificación. El objetivo de este trabajo es entender cómo es el proceso de la reificación de los pescadores tradicionales, el análisis de las categorías definidas como múltiples determinaciones de lo real, en vista de su integración económica y la exclusión social en el sistema del capital. La base teórica de la obra se compone de autores como Marx, Lukács, Adorno, Faria, Horkheimer, Meszaros y otros. Se trata de una investigación cualitativa en una comunidad de pescadores. Se pudo ver en la investigación que la reificación, entre los pescadores más jóvenes, se lleva a cabo por todos los elementos (en materia de trabajo y bienes) responsables de la transformación del sujeto en un instrumento de capital. Es la transformación de la condición de que el productor de la mercancía, con todas sus propiedades. La reificación está también relacionada con el trabajo alienado y que, a pesar de la tendencia hegemónica del sistema capitalista de producción, es posible identificar la resistencia en relación con este proceso de reificación. En pocas palabras, no habría una reificación que esté relacionado con el trabajo alienado y que, a pesar de la tendencia hegemónica del sistema capitalista de producción, se puede identificar la resistencia ese proceso de reificación.

\section{palaBRAS CLAVE}

Gestión; Pesca artesanal; Reificación; Alienación; Trabajo. 


\section{REFERÊNCIAS}

ADORNO, T. W. Dialéctica negativa. Madrid: Taurus, I975.

BARDIN, L. Análise de conteúdo. Lisboa: Edições 70, I979.

FARIA, J. H. de. Tecnologia e processo de trabalho. Curitiba: Ed. UFPR, I992. . Economia política do poder: Fundamentos. Curitiba: Juruá, 2004. v. I.

Gestão participativa: relações de poder e de trabalho nas organizações. São Paulo: Atlas, 2009. . Epistemologia, metodologia e interdisciplinaridade. Curitiba: FAE-PR/PMOD, 20II. Work-

ing Paper.

FRASER, N. Escalas de justicia. Barcelona: Herder Ed., 2008.

HORKHEIMER, M. Eclipse da razão. São Paulo: Centauro, 2000.

LUKÁCS, G. Historia y consciencia de clase. México (DF): Edit. Grijalbo, I969. Ontologia do ser social. São Paulo: Ciências Humanas, I979.

MARX, K. Manuscritos econômicos filosóficos. In: FROMM, E. Conceito marxista do homem. 4. ed. Rio de Janeiro: Zahar, 1967. . Contribuição à crítica da economia política. São Paulo: Martins Fontes, I983a. . O capital: crítica da economia política. São Paulo: Abril Cultural, I983b. O capital: crítica da economia política. Rio de Janeiro: Civilização Brasileira, I99I.

MARX, K.; ENGELS, F. A ideologia alemã. São Paulo: Martins Fontes, 200 I.

MATOS, O. C. F. Os arcanos do inteiramente outro. 2. ed. São Paulo: Brasiliense, I995.

MÉSZÁROS, I. Para além do capital. São Paulo: Boitempo, 2002. . A teoria da alienação em Marx. São Paulo: Boitempo, 2006. 